\title{
UNSUPERVISED ANN BASED PID CONTROLLER FOR A SUPERCONDUCTING GENERATOR IN A MULTI-MACHINE POWER SYSTEM
}

\author{
G. A. Morsy \\ R. A. Amer \\ H. A. Yassin \\ Electrical Engineering Department, Faculty of Engineering, \\ Minoufiya University, Shebin El-Kom, Egypt
}

\begin{abstract}
The paper presents an artificial neural network (ANN) based Proportional Integral Derivative (PID) controller for a superconducting generator (SCG) in a multi-machine power system. The studied power system includes a SCG and three conventional machines of different types and ratings. The SCG is controlled also by conventional PID, which is designed according to pole placement technique, implemented in its governor control loop. While, conventional generating units are controlled by different conventional excitation control systems. The ANN controller patterns are gathered from a simple unsupervised (self learning) ANN-PID using an optimization technique. To achieve a high degree of accuracy, the system is represented by a fairly detailed non-linear model. The simulation results reveal that, the proposed ANN controller is achieving further enhancement of the system performance in terms of damping increase and fast return of system variables to their nominal values over a wide range of operating conditions and under sever disturbances such as 3-phase short circuit, step increase in load, and 3-phase short circuit followed by one line outage compared to conventional PID controller.

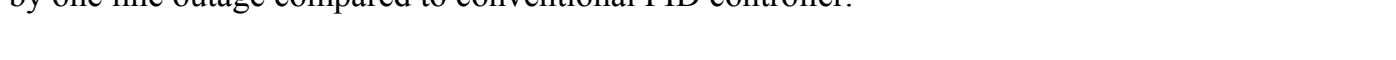

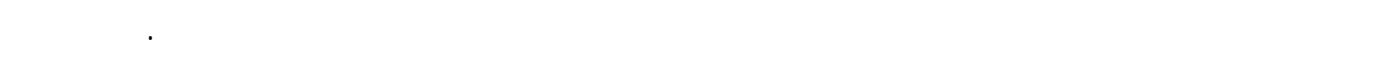

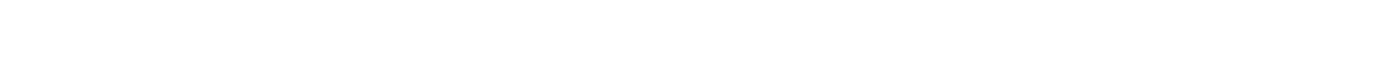

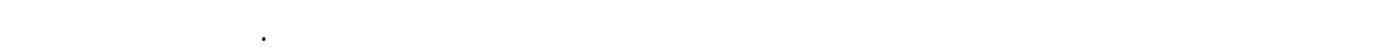

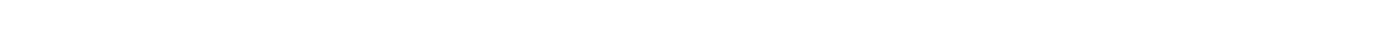

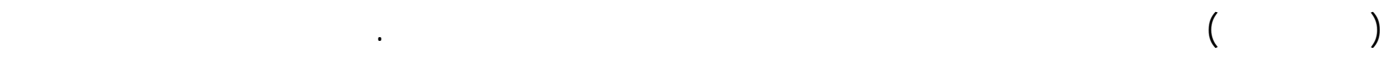

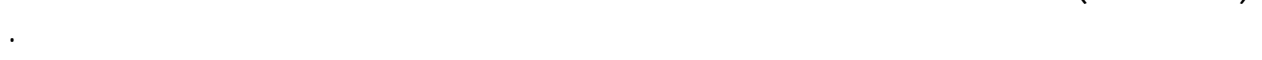

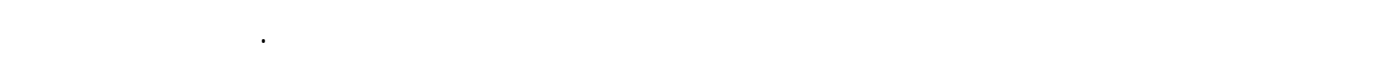

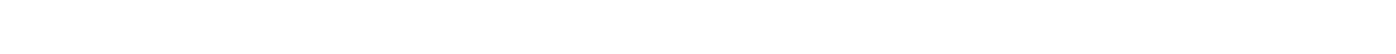

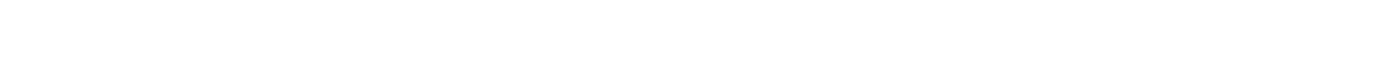

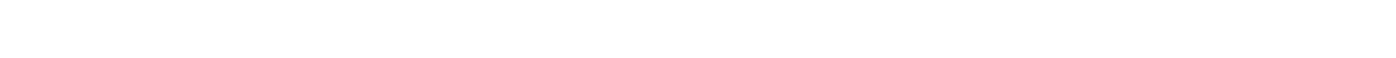

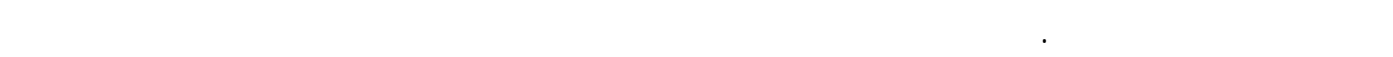

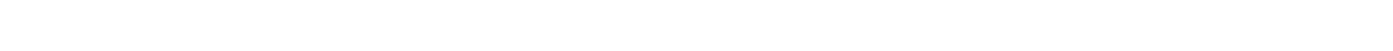

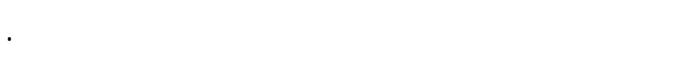

Keywords: Multi-machine power system control, Superconducting generator, ANN control.

\section{INTRODUCTION}

Stabilization of SCGs in multi-machine power systems is optimum choice to overcome the up-rating problems of conventional synchronous generators, which tends to use parameters adversely affect the system stability [1]. SCGs have many advantages over conventional synchronous machines as the capability of generating greater power with higher efficiency, possibility of generation at transmission line voltages, reduced size and weight and low p.u. reactance as well as environmental advantages due to reduced oil consumption and $\mathrm{CO}_{2}$ emissions [2]. However, SCGs have a complicated structure due to the fact that SCG field winding has a high current density which obviates the need for any magnetic circuit in the SCG. So, the armature windings are air cored. Also, a helium management system and two eddy-current screens are incorporated in the rotor field windings $[3,4]$. The outer screen acts as a damper for damping purpose and the inner screen acts as an electromagnetic shield that, shields the field winding from time changing magnetic filed [5]. In view of control, conventional machines are controlled via their excitation loops. While, SCG which has high hunting frequency and low inherent damping, requires a special attention and more considerations due to the field winding zero resistance and the corresponding extreme long time constant, which makes the SCG excitation control ineffective [6,7]. Hence, the governor control loop is the only permissible loop to enhance performance of 


\section{G. A. Morsy, R. A. Amer, H. A. Yassin, "Unsupervised ANN Based PID Controller for a Superconducting ..."}

the SCG. Various conventional controllers with fixed parameters have been employed to control the SCG as phase advance, PI, and PID. These conventional controllers are designed at a certain operating condition. Due to the load changes or other disturbances, the power system operating conditions daily change. So, these fixed parameters controllers which insure good performance under a certain operating condition may be not suitable for other conditions. To maintain better performance under a wide range of operating conditions, self tuning adaptive controllers have been developed [8]. The self tuning controller design difficulty is summarized in the system suitable identification algorithm to imitate the actual system behavior in wide range of operating conditions.

Research in ANNs has been recently active as a new means of processing and became the focus of much attention, due to their wide range of applicability and the ease with which they can handle complex and nonlinear problems. Also, ANNs have many advantages, as rapidity due to the parallel mechanism, the memorization ability, robustness, fault tolerance, and adaptability which have attached attention in many fields. Since 1989, ANNs methodology have capture and interest in electrical power engineering and it is promise to ensure effective ANN controllers, which can enhance system performance, if it properly trained. Many published researches have been developed ANN controllers for conventional generators and SCGs which trained using conventional schemes $[9,10]$.

The object of this paper is to apply an alternative control approach using the ANN control strategy to improve the performance of the low inherent damping and high hunting frequency SCG in a multimachine power system. The ANN scheme was trained by patterns gathered from on-line simple unsupervised (self learning) ANN-PID attached in the governor loop using an optimization technique to minimize the system deviations under various operating conditions. The simple ANN-PID consists of one input, one hidden, and one output layers. However, the proposed ANN that attached to the SCG in its operation consists of one input, two hidden, and one output layers. The system performance with ANN controller on SCG is compared with others using conventional PID controller on SCG and at each case the excitation control with power system stabilizer (PSS) network is applied to conventional units. The simulation results illustrate that the system with ANN controller on SCG is more stable and robust when subjected to various disturbances in different operating conditions.

\section{STUDIED POWER SYSTEM}

The single line diagram of the studied electrical power system is shown in Fig. 1. The concerned multi-machine power system is a twelve buses, eight double-circuit transmission lines, four transformers, four generating units, and four load areas. All loads treated as lumped impedances and the transmission lines are represented by $\pi$ method. The generating units are of different types and ratings as follow: a thermal unit 590 MVA $\left(\mathrm{G}_{1}\right)$ is connected to busbar 1 , a 1300 MVA nuclear unit $\left(\mathrm{G}_{2}\right)$ attached to busbar 2, a 2000 MVA SCG unit $\left(\mathrm{G}_{3}\right)$ connected to busbar 3, and a hydro-electric 615 MVA unit $\left(\mathrm{G}_{4}\right)$ at busbar 4. Each generator is linked to the system by a step-up transformer. Network parameters are shown in Fig. 1 and Table 1. A MATLAB Simulink model has been built to simulate the studied system. The system nonlinear equations are solved using Runge-Kutta integration technique with $0.2 \mathrm{~ms}$ integration step. The generating units parameters are listed in Appendix A.

\section{CONVENTIONAL GENERATORS CONTROL}

In this study, conventional generators are controlled via excitation control using Various types of exciters with different ceiling voltages. In this control scheme the steam generator is equipped with fast acting thyristor exciter with negligible time lag. The other two conventional machines are equipped with rotary exciter type. A high gain automatic voltage regulator (AVR) is used with the exciter to control the generator terminal voltage. The block diagram of the excitation system for conventional generators is shown in Fig.2. The excitation system parameters are listed in Appendix A according to the IEEE standardization.

Under heavy load conditions the continuously acting of excitation systems produce a negative damping to the system oscillations. To eliminate that bad effect and in general to improve the system damping, an artificial network producing torque in the speed phase is introduced. The network used to add a signal that control the synchronous machine terminal voltage is called power system stabilizer (PSS) network [11]. The PSS is a lead-lag network with two time constants $T_{1}$ and $T_{2}$ and gain $G_{s}$. The PSS attached to the excitation system is shown in Fig. 2.

The PSS parameters are designed individually for each machine [1]. The PSS transfer function is given by:

$$
\frac{\mathrm{y}_{\mathrm{S}}}{\Delta \omega}=\mathrm{Gs} \frac{1+\mathrm{T}_{1} \mathrm{~s}}{1+\mathrm{T}_{2} \mathrm{~s}}
$$

where, $y_{s}$ is the control signal, and $\Delta \omega$ is the deviation in machine speed. The ratio $T_{1} / T_{2}$ is 10 [11].

To reduce the order of the system, it is assumed that mechanical input torque to each conventional machine is fixed. 


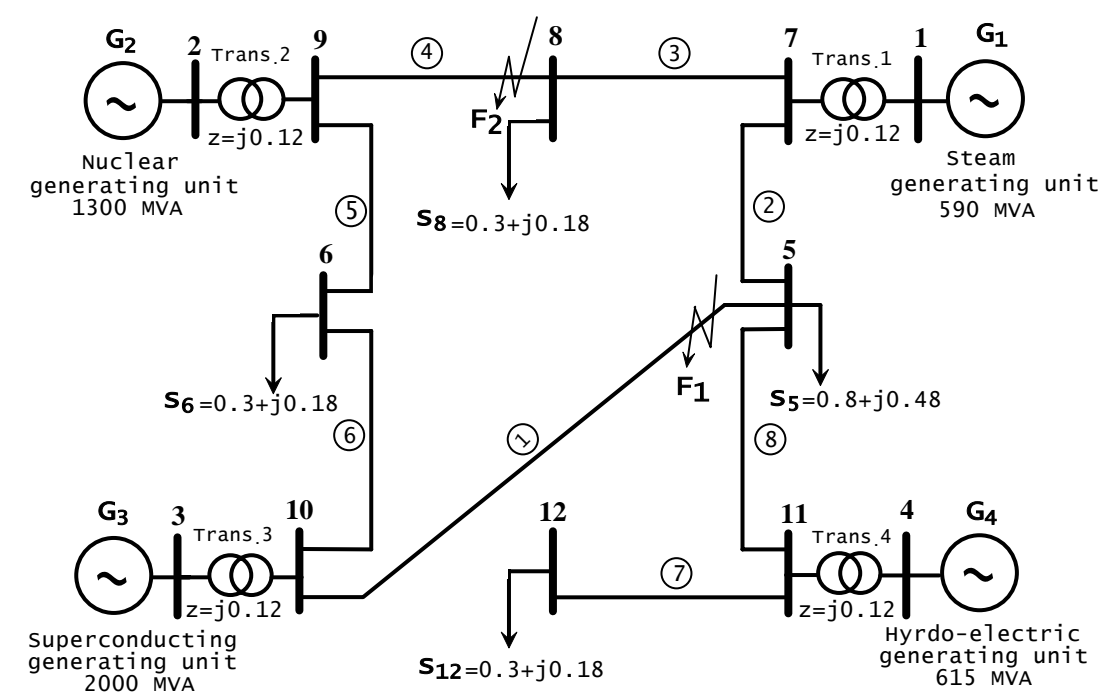

Fig. 1 Single line diagram of the studied Multi-machine power system

Table 1 Transmission lines parameters

\begin{tabular}{|c|c|c|c|}
\hline Line & $\mathbf{1 , 4 , 6 , 8}$ & $\mathbf{2 , 3 , 5}$ & $\mathbf{7}$ \\
\hline Impedance & $0.009+\mathrm{j} 0.1$ & $0.009+\mathrm{j} 0.15$ & $0.018+\mathrm{j} 0.3$ \\
\hline Admittance & $\mathrm{j} 0.07$ & $\mathrm{j} 0.07$ & $\mathrm{j} 0.035$ \\
\hline
\end{tabular}

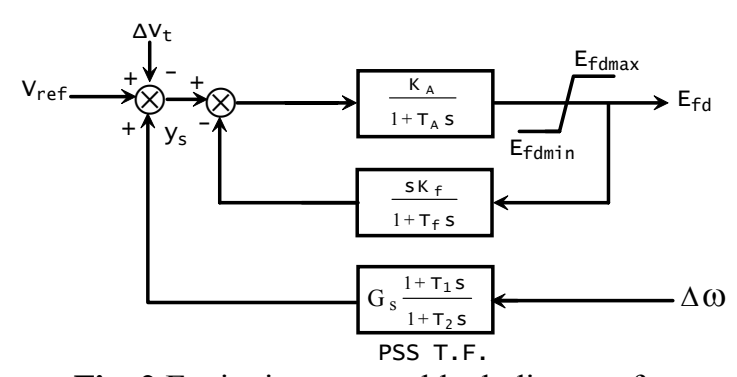

Fig. 2 Excitation system block diagram for conventional generating units

\section{SCG CONTROL}

Excitation control is ineffective in improving the performance of the SCG due to the very long time constant of its field winding and the shielding effects of the two rotor screens, which is designed to protect the superconducting field winding from armature transients, also prevents any events in the field winding to be effective at the stator winding. Moreover, the magnitude and rate of change of the excitation current and field flux must not exceed certain limits, otherwise the superconducting element goes normal (quench) [12]. So, this renders the necessity of considering only the governor control loop to enhance the system performance [9]. Adding positive damping via the governor loop is very difficult and requires a great deal of attention [13]. The SCG is driven by a three stages steam turbine system with reheat and fast acting electro-hydraulic governor. The model of the SCG turbine, and speed governor are illustrated in Appendix B. In this study conventional PID is used as well as the proposed
ANN controller through a selector to connect the desired controller to the system as shown in Fig. 3 .

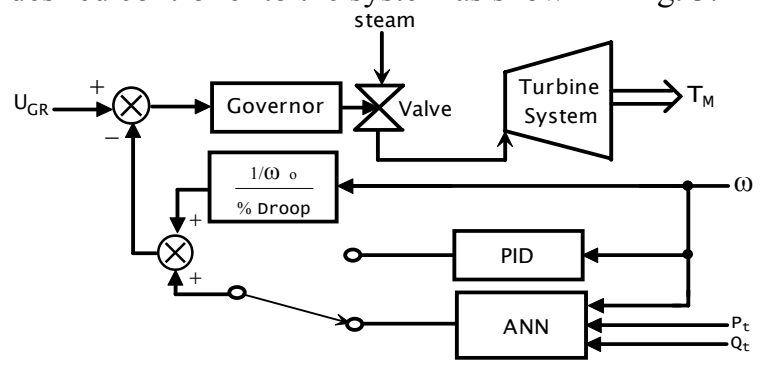

Fig. 3 The SCG control system

\subsection{Conventional PID Controller}

The performance of the SCG can be improved by incorporating conventional controllers in the governor loop. The used conventional controller in.

this study is the PID controller, which is designed according to the pole placement technique for the linearized model of the single SCG connected to an infinite bus $[6,14]$. The PID controller is introduced to enhance the system performance and to add positive damping.

The closed-loop pole locations have a direct impact on time response characteristics such as rise time, settling time, and transient oscillations. The PID controller transfer function is given by:

$\mathrm{H}(\mathrm{s})=\mathrm{K}_{\mathrm{p}}+\frac{\mathrm{K}_{\mathrm{i}}}{\mathrm{s}}+\mathrm{sK}_{\mathrm{d}}$

where, $\mathrm{K}_{\mathrm{p}}, \mathrm{K}_{\mathrm{i}}$, and $\mathrm{K}_{\mathrm{d}}$ are the PID controller parameters. The PID controller parameters values are obtained as $0.182668,0.000125366$, and 0.072285 respectively. 


\subsection{ANN NETWORKS}

This section presents two different groups of ANNs. The first group is designed to obtain the patterns groups which, are used in training the second ANNs group.

\subsubsection{The Simple ANN-PID}

To obtain the values of PID parameters a simple ANN is established to control the system with weights and biases adjustment. The ANN parameters adjustment is done by minimizing the system performance index, which indicates the system deviation. The system performance index (p.index), which is the total sum of the system deviations multiplied by time as:

$$
\text { p. index }=\int_{0}^{\infty} \mathrm{e}(\mathrm{t}) \mathrm{*t}^{2}
$$

where, $\mathrm{e}(\mathrm{t})=\sum$ \{output deviations in speed, rotor angle for each machine, and SCG valve position. $\}$, $\mathrm{t}$ : is the time.

The purpose of the simple ANN-PID net is to generate patterns at various conditions. the implementation of optimized ANN-PID controller that uses on-line tuning of the PID parameters based on an optimization technique that minimize the system deviations of the normal values [15]. The minimization of the performance index is accrued by the help of the Matlab function least-squares-nonlinear problem solver called " 1sqnonlin" [16]. The inputs of the simple ANN are the SCG terminal active and reactive powers and its output is only one PID parameter as $K_{p}, K_{i}$, or $K_{d}$ so, the simple ANN is repeated three times one for each controller parameter. Fig. 4 shows the construction of one net of that ANNs group, which consists of one input layer, one hidden layer (2-neurons) with a hyperbolic tangent sigmoid activation function, and one output with a pureline activation function.

This ANN parameters are tuned at different operating conditions according to performance index minimization at each case. Now several values of $K_{p}$, $\mathrm{K}_{\mathrm{i}}$ and $\mathrm{K}_{\mathrm{d}}$ according to the SCG terminal active and reactive powers are obtained. These groups of patterns are shown in Fig. 5 for two different operating conditions.

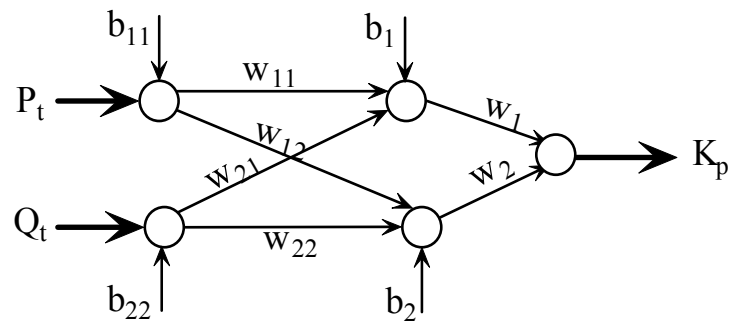

Fig. 4 The architecture of one on-line simple ANN-PID

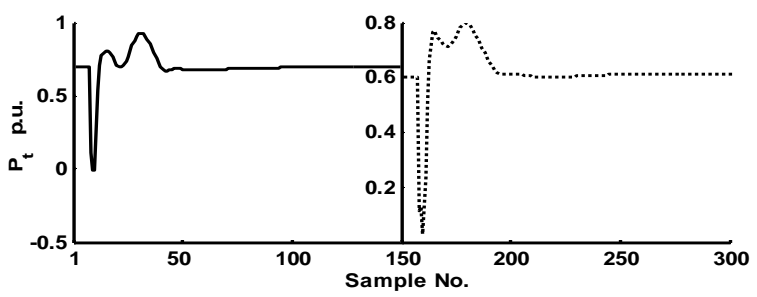

(a) First input patterns

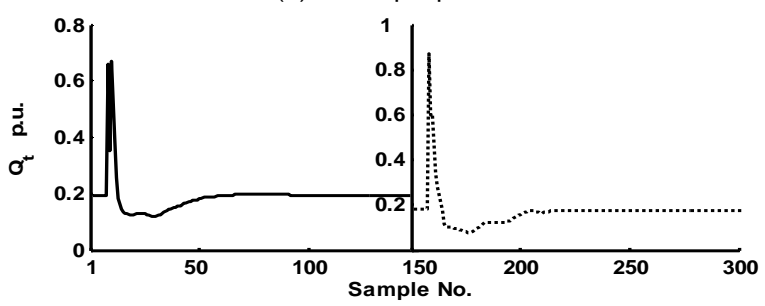

(b) Second input patterns

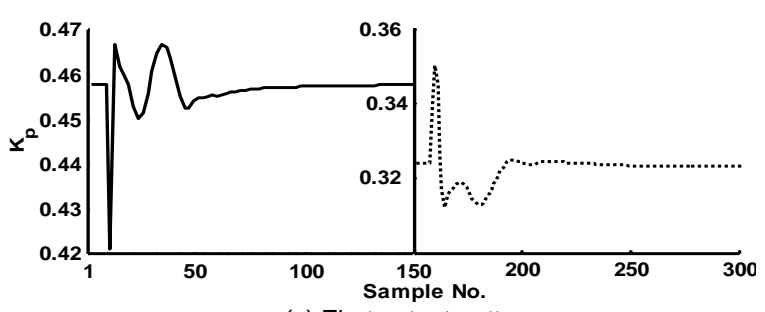

(c) First output patterns

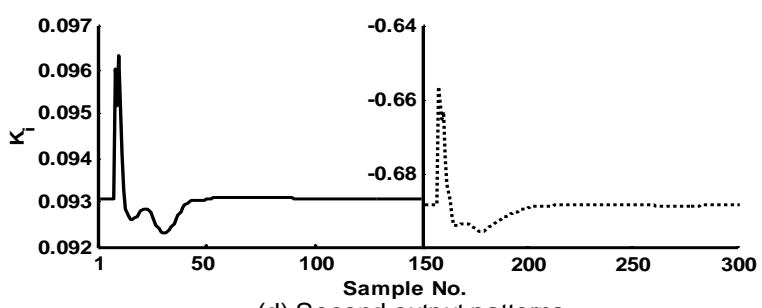

(d) Second output patterns

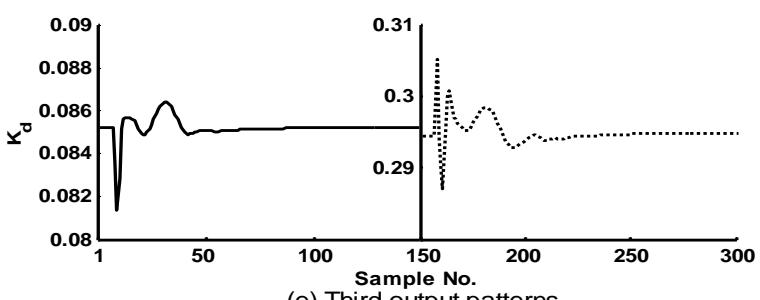

(e) Third output patterns

Fig. 5 The simple ANN-PID patterns groups

\subsubsection{The Proposed ANN Controller}

Another ANN is established to be trained on the results of the first simple ANN patterns. The second ANN, which is used for system control, consists of one input layer, first hidden (20-neurons) with hyperbolic tangent sigmoid activation function, second hidden layer (10- neurons) with log sigmoid activation function, and one output layer with a pureline activation function. Also, three ANNs are used, one for each controller parameter. The architecture of one of these ANNs is shown in Fig. 6. The complete ANN controller system is illustrated in Fig. 7. 


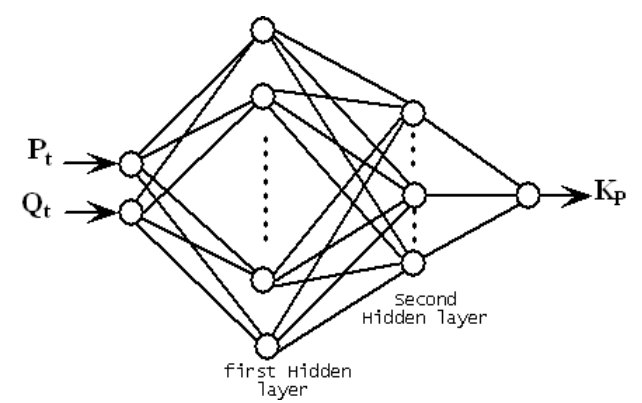

Fig. 6 The architecture of one ANN

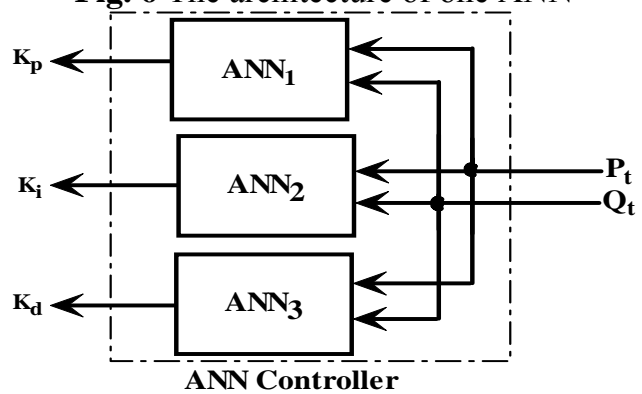

Fig. 7 The ANN controller with all components

\section{Back Propagation Algorithm}

The training algorithm used here is The LevenbergMarquardt back propagation approach. This approach procedures are:

1-Enter the net training parameters shown in Table 2.

2-Weights and biases initialization: in this step all weights and the thresholds to nodes (biases) set to small random numbers.

3-Calculate the Jacobian matrix ( $\mathrm{J})$ that contains first derivatives of the network errors with respect to the weights and biases, the network errors vector (e) between the net outputs and the desired targets, the gradient (grad.), and the performance (Perf.) according to mean-square-error.

$\mathrm{e}_{\mathrm{i}}=\left\{\right.$ Target $_{\mathrm{i}}-$ net.out $\left._{\mathrm{i}}\right\}$, grad. $=\sqrt{\mathrm{J}^{\mathrm{T}} \mathrm{e} \mathrm{J} \mathrm{e}}$, and

Perf. $=\frac{1}{\mathrm{~N}} \sum_{\mathrm{i}=1}^{\mathrm{N}} \mathrm{e}_{\mathrm{i}}{ }^{2}$

where, $\mathrm{N}$ is the number of targets.

4-Calculate $\mathrm{dX}$ vector denoted the increment in each weight and bias from the relation:

$$
\mathrm{dX}=-\left(\mathrm{J}^{\mathrm{T}} \mathrm{J}+\mu \mathrm{I}\right)^{-1} \mathrm{~J}^{\mathrm{T}} \mathrm{e}
$$

where, $\mathrm{J}$ is the Jacobian matrix, $\mathrm{I}$ is identity matrix, $\mathrm{e}$ is the network errors vector, and $\mu$ is a damping factor, a non-negative scalar value adjusted at each iteration.

5-Calculate the new values of the weights and biases from the relation:

$$
\mathrm{X}_{\mathrm{k}+1}=\mathrm{X}_{\mathrm{k}}+\mathrm{dX}
$$

6- Calculate the new performance, if the new performance is less than the previous then:

a-Accept the new weights and biases (net parameters).

b-Reduce $\mu$ by times of $\mu_{d}$ i.e. $\mu=\mu^{*} \mu_{d}$ where, $\mu_{d}$ is the decrement in the damping factor.
Else, don't change weights and biases and increase $\mu$ by times of $\mu_{i}$ i.e. $\mu=\mu^{*} \mu_{i}$ where, $\mu_{i}$ is the increment in the damping factor

7-Repeat step 2 to step 6 till the stopping criterion occurs.

The Levenberg-Marquardt training technique exists in Matlab in m-file function called "Trainlm".

Table 2 Network training parameters in LevenbergMarquardt technique

\begin{tabular}{|l|c|c|}
\hline Parameter & Symbol & Value \\
\hline Iterations (epochs) & ---- & 5000 \\
\hline mean of error squared (goal) & ---- & $10^{-10}$ \\
\hline damping factor initial value & $\mu$ & 0.001 \\
\hline Decrement in damping factor & $\mu_{\mathrm{d}}$ & 0.1 \\
\hline Increment in damping factor & $\mu_{\mathrm{i}}$ & 10 \\
\hline Maximum damping factor & $\mu_{\max }$ & $10^{10}$ \\
\hline Minimum gradient value & grad.min & $10^{-10}$ \\
\hline
\end{tabular}

\section{ANN Training}

The Levenberg-Marquardt algorithm is used to train the net for the simple ANN result patterns. the training of PID parameters against epochs are shown in Fig. 8. The figure illustrates that the goal reached for each parameter.
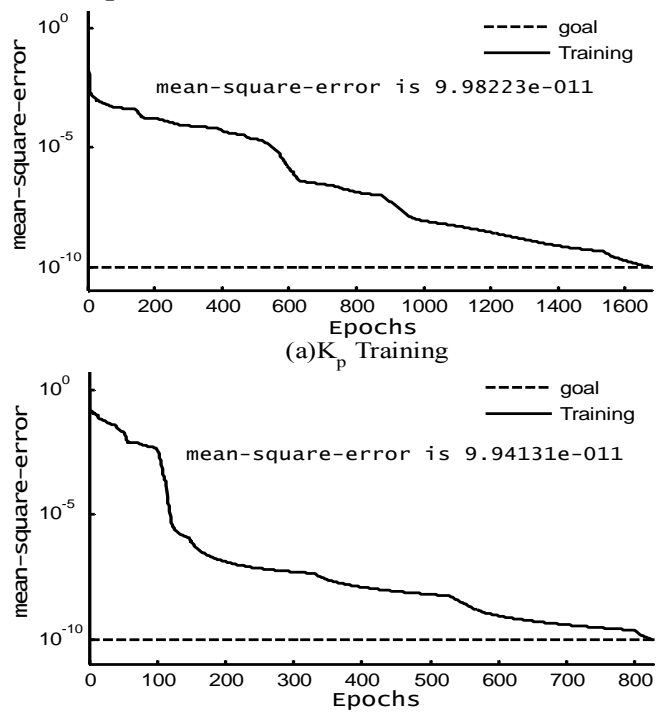

(b) $\mathrm{K}_{\mathrm{i}}$ Training

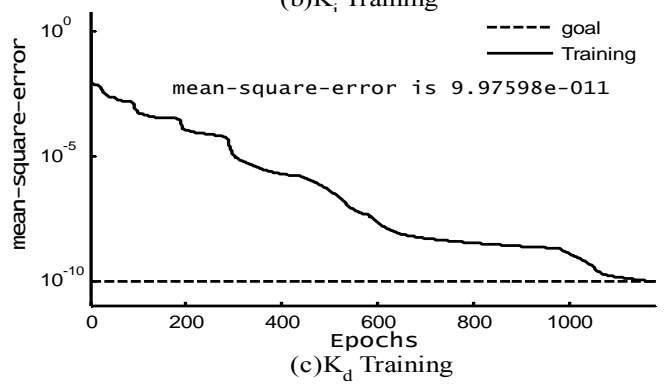

Fig. 8 The training of PID parameters

\section{Operating Conditions}

In this study, the multi-machine power system operates at two different operating conditions. These 
two operating conditions are represented by each machine apparent power and bus terminal voltage as described in Appendix A as a result of load flow calculations.

\section{SIMULATION RESULTS}

The proposed ANN controller has been implemented for SCG in a multi-machine power system in its governor control loop and the system performance examined for various types of disturbances at different operating conditions. To illustrate the effectiveness of the proposed ANN controller a fairly detailed non-linear model of the system is used and the simulation results are compared with others, obtained using the conventional PID controller attached to SCG. Conventional machines are equipped with conventional AVRs with PSSs. The system response for a symmetrical three-phase short circuit for $100 \mathrm{~ms}$ duration, is shown in Fig. 9, for $10 \%$ load increase at bus 5 for $100 \mathrm{~ms}$ is shown in Fig. 10, and for a symmetrical three-phase short circuit for $100 \mathrm{~ms}$ duration followed by one line outage of the double transmission line for $150 \mathrm{~ms}$ is shown in Fig. 11. These results illustrate that the ANN controller is more reliable than conventional controllers as it provide a good damping to the electro-mechanical modes of oscillations and all system variables quickly return to their initial values. Also, the SCG is the dominant machine in this studied system. So, enhancing its control system makes its performance better and the whole system performance becoming better. The improvement of the system performance with ANN controller is clear at the load step increase than the conventional PID controller. As, the ANN controller is dependable on the system operating conditions.

\section{CONCLUSIONS}

The paper presents an ANN methodology based PID controller as an alternative approach to improve the performance of a SCG in a multi-machine power system. Conventional generating units in the system are equipped with conventional control systems. While, SCG is equipped with proposed ANN controller in its governor loop. To overcome the conventional controllers fixed parameters problem, the data patterns are gathered from simple ANN-PID systems trained on-line at some different operating conditions when the system is subjected to disturbances. Then, the proposed ANN was trained using the obtained patterns from the on-line ANNPID. Then, the trained ANN controller is used to control the SCG. Also, a conventional PID controller designed using the pole placement technique for the SCG is used and the system results are obtained in comparative form with those obtained using the proposed ANN controller. The simulation results, show the effectiveness of the ANN controller over the conventional controller for various disturbances at a wide range of operating conditions in terms of damping increase, system variables fast return to their nominal values and less movements of the SCG governor valve.

\section{REFERENCES}

[1] S. M. Osheba et al, "Comparison of transient performance of superconducting and conventional generators in a multimachine system“, IEE-Proc.135, pt. C, No. 5, Sept. 1988, pp.389-395.

[2] H. A. Khattab, "Stabilization Of A Superconducting Generating Unit In A Multimachine System", Ph.D. Thesis, Menoufia University, Faculty of Eng. 2007.

[3] A. H. M. S. Ula, et al., "The effect of design parameters on the dynamic behavior the superconducting alternators", IEEE Trans. on EC, Vol. 3, No. 1, March 1988.

[4] K. Yamagushi, et al., "Rotor design of a 1000 MW superconducting generator", IEEE Trans. on EC, Vol. 4, No. 2, June 1989.

[5] M. A. Alyan and Y. H. Rahim, "The role of governor control in transient stability of superconducting turbogenerators", IEEE Trans.EC-2, March1987, pp.38-46

[6] G. A. Morsy, H. A. Kattab and A. Kinawy, "Design of a PI controller for a superconducting generator", Eng. Research. Vol. 23, No. 1, Fac. Of Eng., Men., Univ., pp. 61-77, January 2000.

[7] H. A. Khattab, "Control and Performance Analysis of A Super conducting Generator", M.Sc. thesis, Menoufia University, Faculty of Eng., 2000.

[8] G. P. Chen, O. P. Malik, et al., "An Adaptive power system stabilizer based on the selfoptimizing pole shifting control strategy", submitted to IEEE/PES winter meeting 1993.

[9] G. A. Morsy, T. A. Mohammed, “An ANN Based PI Controller For A Superconducting Generator", Eng. Research. Vol. 24, No. 3, Fac. Of Eng., Men., Univ., pp. 113-125, June 2001.

[10] Zhng et al., "An artificial neural network based adaptive power system stabilizer", IEEE Trans. on EC-8. No. 1, pp. 71-77, March 1993.

[11] A. H .El-abiad, "Power systems analysis and planning", Purdue University, West Lafayette, Indiana USA, 1983.

[12] S. M. Osheba , Y. H. A. Rahim, et al, "Stability of a Multi-Machine System Incorporating a Superconducting Alternator", IEEE Trans. on Energy Conversion, Vol. 3, No.3, Sept.1988.

[13] G. A. Morsy, "Validation of a Flexible Controller for a Superconducting Generator", Eng. Research Journal (ERJ),Faculty of Eng., Minoufia Univ., Egypt Vol.25, No.2, pp.187-199, April 2002. 
G. A. Morsy, R. A. Amer, H. A. Yassin, "Unsupervised ANN Based PID Controller for a Superconducting ..."

[14] Y. Y. Hsu, C. J. Wu, "Design of PID Static VAR Controllers for The Damping Of Subsynchronous Oscillations", submitted to IEEE/PES summer meeting 1987.

[15] R. A. Saleh, "Genetic algorithm- Tuned Fuzzy Logic- Based Governor Controller For A Fully Superconducting Generator", MEPCON'2003, Men. Univ., Dec.16-18, 2003.

[16] Hagan, M. T, and M. Menhaj, "Training feedforward networks with the Marquardt algorithm", IEEE Transactions on Neural Networks, Vol. 5, No. 6, pp. 989-993, 1994.

\section{APPENDICES}

\section{Appendix A}

\section{Superconducting Generator Parameters}

2000 MVA, $1700 \mathrm{MW}, 3000 \mathrm{rpm}$

$\mathrm{X}_{\mathrm{d}}=\mathrm{X}_{\mathrm{q}}=0.5457$ p.u.

$\mathrm{X}_{\mathrm{D} 1}=\mathrm{X}_{\mathrm{Q} 1}=0.2567$ p.u.

$\mathrm{X}_{\mathrm{D} 2}=\mathrm{X}_{\mathrm{Q} 2}=0.4225$ p.u., $\mathrm{X}_{\mathrm{f}}=0.541$ p.u.

$\mathrm{X}_{\mathrm{fd}}=\mathrm{X}_{\mathrm{fD} 1}=\mathrm{X}_{\mathrm{dD} 1}=\mathrm{X}_{\mathrm{dD} 2}=\mathrm{X}_{\mathrm{D} 1 \mathrm{D} 2}=0.237$ p.u.

$\mathrm{X}_{\mathrm{qQ1}}=\mathrm{X}_{\mathrm{qQ} 2}=\mathrm{X}_{\mathrm{Q} 1 \mathrm{Q} 2}=0.237$ p.u., $\mathrm{X}_{\mathrm{fD} 2}=0.3898$ p.u.

$\mathrm{R}_{\mathrm{a}}=0.003$ p.u., $\mathrm{R}_{\mathrm{D} 1}=\mathrm{R}_{\mathrm{Q} 1}=0.1008$ p.u.

$\mathrm{R}_{\mathrm{D} 2}=\mathrm{R}_{\mathrm{Q} 2}=0.00134$ p.u.

Field time constant $=750 \mathrm{~s}$

$\mathrm{H}=3 \mathrm{KW} . \mathrm{s} / \mathrm{KVA}$

\section{Turbines And Governor System Parameters}

$\mathrm{T}_{\mathrm{HP}}=\mathrm{T}_{\mathrm{GM}}=0.1 \mathrm{~s}, \mathrm{~F}_{\mathrm{HP}}=26 \%, \mathrm{~T}_{\mathrm{IP}}=0.1 \mathrm{~s}, \mathrm{~F}_{\mathrm{IP}}=42 \%$

$\mathrm{T}_{\mathrm{LP}}=0.3 \mathrm{~s}, \mathrm{~F}_{\mathrm{LP}}=32 \%, \mathrm{~T}_{\mathrm{HR}}=10 \mathrm{~s}, \mathrm{P}_{\mathrm{O}}=1.2$ p.u.

Table (A-1) Conventional machines parameters

\begin{tabular}{|l|c|c|c|}
\hline Unit & $\mathbf{G}_{\mathbf{1}}$ & $\mathbf{G}_{\mathbf{2}}$ & $\mathbf{G}_{\mathbf{4}}$ \\
\hline $\mathbf{X}_{\mathbf{d}}$ (p.u.) & 2.11 & 2.13 & 0.898 \\
\hline $\mathbf{X}_{\mathbf{q}}$ (p.u.) & 2.02 & 2.07 & 0.646 \\
\hline $\mathbf{X}_{\text {ad }}$ (p.u.) & 1.955 & 1.88 & 0.658 \\
\hline $\mathbf{X}_{\mathbf{F}}$ (p.u.) & 2.089 & 2.12 & 0.724 \\
\hline $\mathbf{X}_{\mathbf{D}}$ (p.u.) & 2.07 & 1.97 & 0.668 \\
\hline $\mathbf{X}_{\mathbf{Q}}$ (p.u.) & 1.93 & 1.88 & 0.457 \\
\hline $\mathbf{R}_{\mathbf{a}}$ (p.u.) & 0.0046 & 0.0029 & 0.0014 \\
\hline $\mathbf{R}_{\mathbf{F}}$ (p.u.) & 0.00013 & 0.00092 & 0.00026 \\
\hline $\mathbf{R}_{\mathbf{D}}$ (p.u.) & 0.02 & 0.018 & 0.012 \\
\hline $\mathbf{R}_{\mathbf{Q}}$ (p.u.) & 0.024 & 0.0212 & 0.02 \\
\hline $\mathbf{H}_{\text {(kw.s/kVA) }}$ & 2.32 & 2.52 & 5.15 \\
\hline
\end{tabular}

Table (A-2) Conventional generating units excitation and PSSs parameters

\begin{tabular}{|l|c|c|c|}
\hline Unit & $\mathbf{G}_{\mathbf{1}}$ & $\mathbf{G}_{\mathbf{2}}$ & $\mathbf{G}_{\mathbf{4}}$ \\
\hline $\mathbf{K}_{\mathbf{A}}$ & 200 & 400 & 200 \\
\hline $\mathbf{T}_{\mathbf{A}}$ & 0.3575 & 0.02 & 0.02 \\
\hline $\mathbf{T}_{\mathbf{f}}$ & 1.0 & 0.04 & 1.0 \\
\hline $\mathbf{K}_{\mathbf{f}}$ & 0.0529 & 0.05 & 0.01 \\
\hline $\mathbf{E}_{\mathbf{f d m i n}}$ & -5.73 & 0.0 & 0.0 \\
\hline $\mathbf{E}_{\mathbf{f d m a x}}$ & 5.73 & 4.46 & 7.32 \\
\hline $\mathbf{G}_{\mathbf{S}}$ & 0.03 & 0.03 & 0.04 \\
\hline $\mathbf{T}_{\mathbf{1}}$ & 0.15 & 0.15 & 0.15 \\
\hline $\mathbf{T}_{\mathbf{2}}$ & 0.015 & 0.015 & 0.015 \\
\hline
\end{tabular}

Table (A-3) The power system operating conditions

\begin{tabular}{|c|c|c|c|c|}
\hline \multirow{2}{*}{ Unit } & \multicolumn{2}{|c|}{ operating point 1 } & \multicolumn{2}{c|}{ operating point 2 } \\
\cline { 2 - 5 } & $\mathbf{S}_{\mathbf{t}}$ (p.u.) & $\mathbf{V}_{\mathbf{t}}$ (p.u.) & $\mathbf{S}_{\mathbf{t}}$ (p.u.) & $\mathbf{V}_{\mathbf{t}}$ (p.u.) \\
\hline $\mathbf{G}_{\mathbf{1}}$ & $0.21+\mathrm{j} 0.14$ & $1.01 \angle 0^{\circ}$ & $0.46+\mathrm{j} 0.14$ & $1.01 \angle 0^{\circ}$ \\
\hline $\mathbf{G}_{\mathbf{2}}$ & $0.5+\mathrm{j} 0.11$ & $1.01 \angle 4.1^{\circ}$ & $0.3+\mathrm{j} 0.095$ & $1.01 \angle-1.4^{\circ}$ \\
\hline $\mathbf{G}_{\mathbf{3}}$ & $0.7+\mathrm{j} 0.2$ & $1.01 \angle 5^{\circ}$ & $0.6+\mathrm{j} 0.18$ & $1.01 \angle 0.9^{\circ}$ \\
\hline $\mathbf{G}_{\mathbf{4}}$ & $0.3+\mathrm{j} 0.26$ & $1.01 \angle-1.4^{\circ}$ & $0.35+\mathrm{j} 0.25$ & $1.01 \angle-3^{\circ}$ \\
\hline
\end{tabular}

\section{Appendix B}

\section{Turbine and governor system for SCG}

The model of the three stages steam turbine with reheat and electro-hydraulic governor is the IEEE standard representation is shown in Fig. (B-1) .

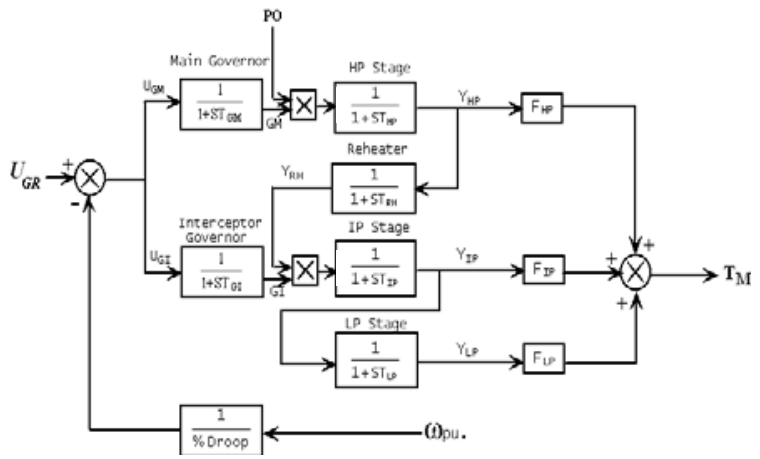

Fig. (B-1) Representation of turbine and governor system The mathematical model of the governor and turbine system is represented by a set of first order differential equations as:

I-The Electro-Hydraulic Governors Equations:

$$
\begin{aligned}
& p G_{M}=\frac{U_{G M}-G_{M}}{T_{G M}} \\
& p G_{I}=\frac{U_{G I}-G_{I}}{T_{G I}}
\end{aligned}
$$

The valves travel and velocity limits are:

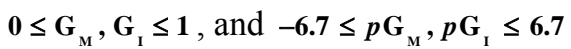

These rate change limits are based on the time required to reach the valves positions to $100 \%$ which is $150 \mathrm{msec}$ [5].

II-Turbines Equations:

$$
\begin{aligned}
& p Y_{\mathrm{HP}}=\frac{\mathrm{G}_{\mathrm{M}} \mathrm{P}_{\mathrm{O}}-\mathrm{Y}_{\mathrm{HP}}}{\mathrm{T}_{\mathrm{HP}}} \\
& p \mathrm{Y}_{\mathrm{RH}}=\frac{\mathrm{Y}_{\mathrm{HP}}-\mathrm{Y}_{\mathrm{RH}}}{\mathrm{T}_{\mathrm{RH}}} \\
& p \mathrm{Y}_{\mathrm{IP}}=\frac{\mathrm{G}_{\mathrm{I}} \mathbf{Y}_{\mathrm{RH}}-\mathrm{Y}_{\mathrm{IP}}}{\mathrm{T}_{\mathrm{IP}}} \\
& p \mathrm{Y}_{\mathrm{LP}}=\frac{\mathrm{Y}_{\mathrm{IP}}-\mathbf{Y}_{\mathrm{LP}}}{\mathrm{T}_{\mathrm{LP}}}
\end{aligned}
$$

The mechanical torque is given by:

$$
\mathbf{T}_{\mathrm{m}}=\mathrm{F}_{\mathrm{HP}} \mathbf{Y}_{\mathrm{HP}}+\mathbf{F}_{\mathrm{IP}} \mathbf{Y}_{\mathrm{IP}}+\mathbf{F}_{\mathrm{LP}} \mathbf{Y}_{\mathrm{LP}}
$$



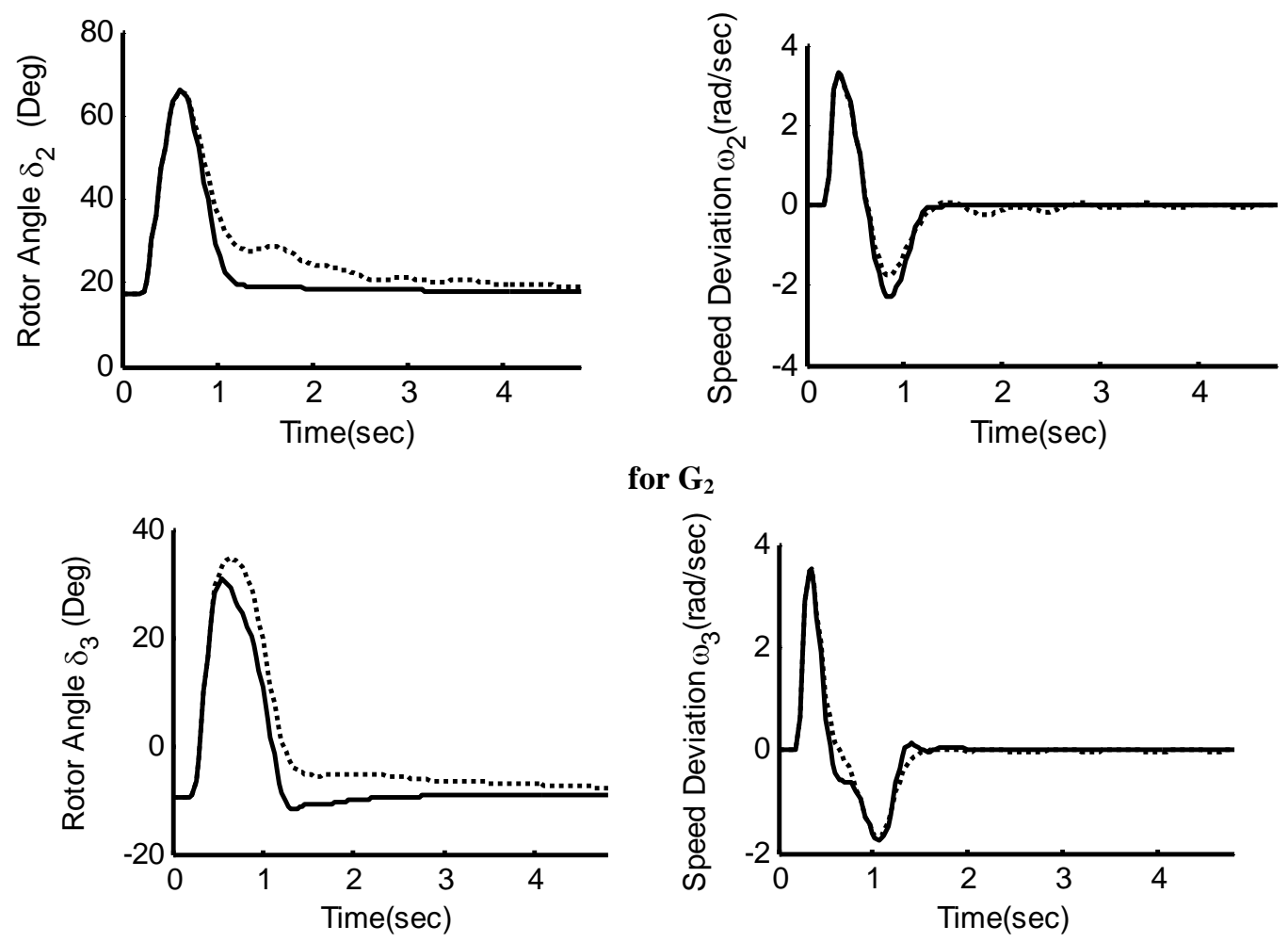

for $\mathbf{G}_{2}$
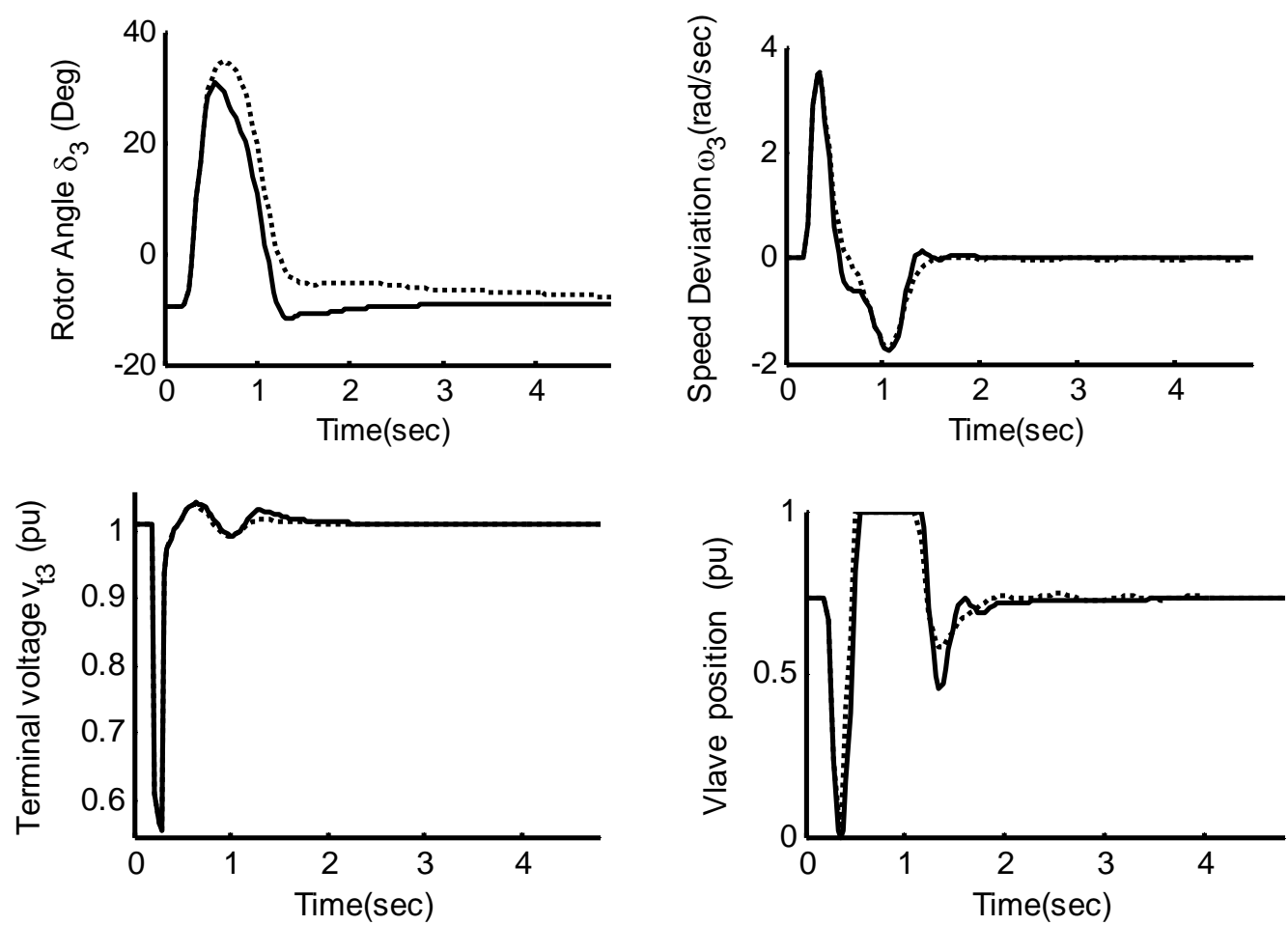

for $G_{3}$
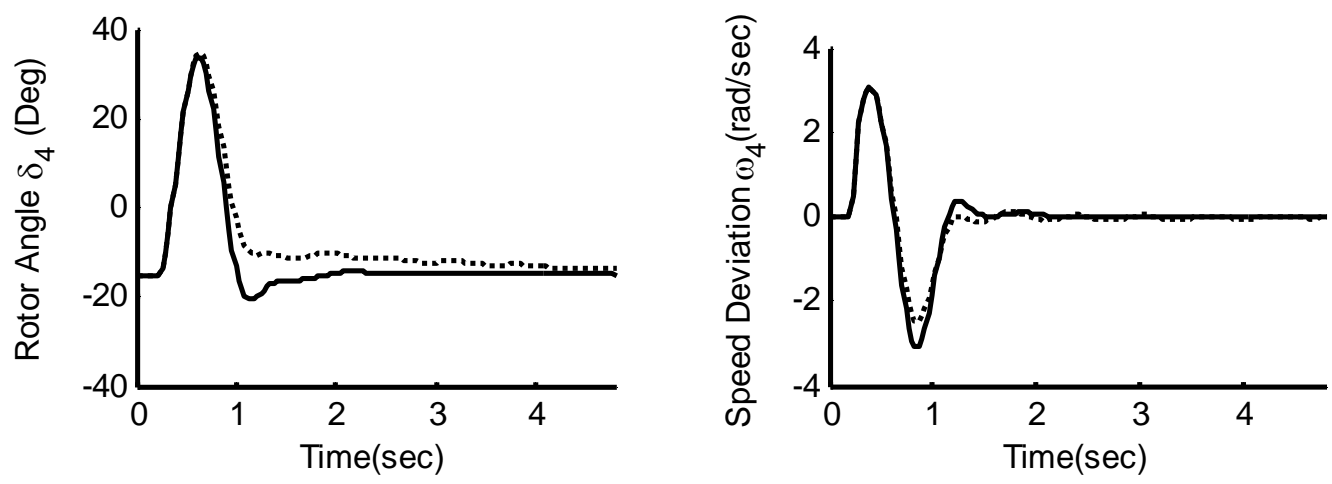

for $\mathbf{G}_{4}$

Fig. 9 Transient response to a 3-phase short circuit for a $100 \mathrm{~ms}$ at $\mathrm{F}_{2}$ followed by one line outage for $150 \mathrm{~ms}$ at operating condition 1

- ANN controller on SCG + PSS on conventional units

......... PID controller on SCG + PSS on conventional units 
G. A. Morsy, R. A. Amer, H. A. Yassin, "Unsupervised ANN Based PID Controller for a Superconducting ..."
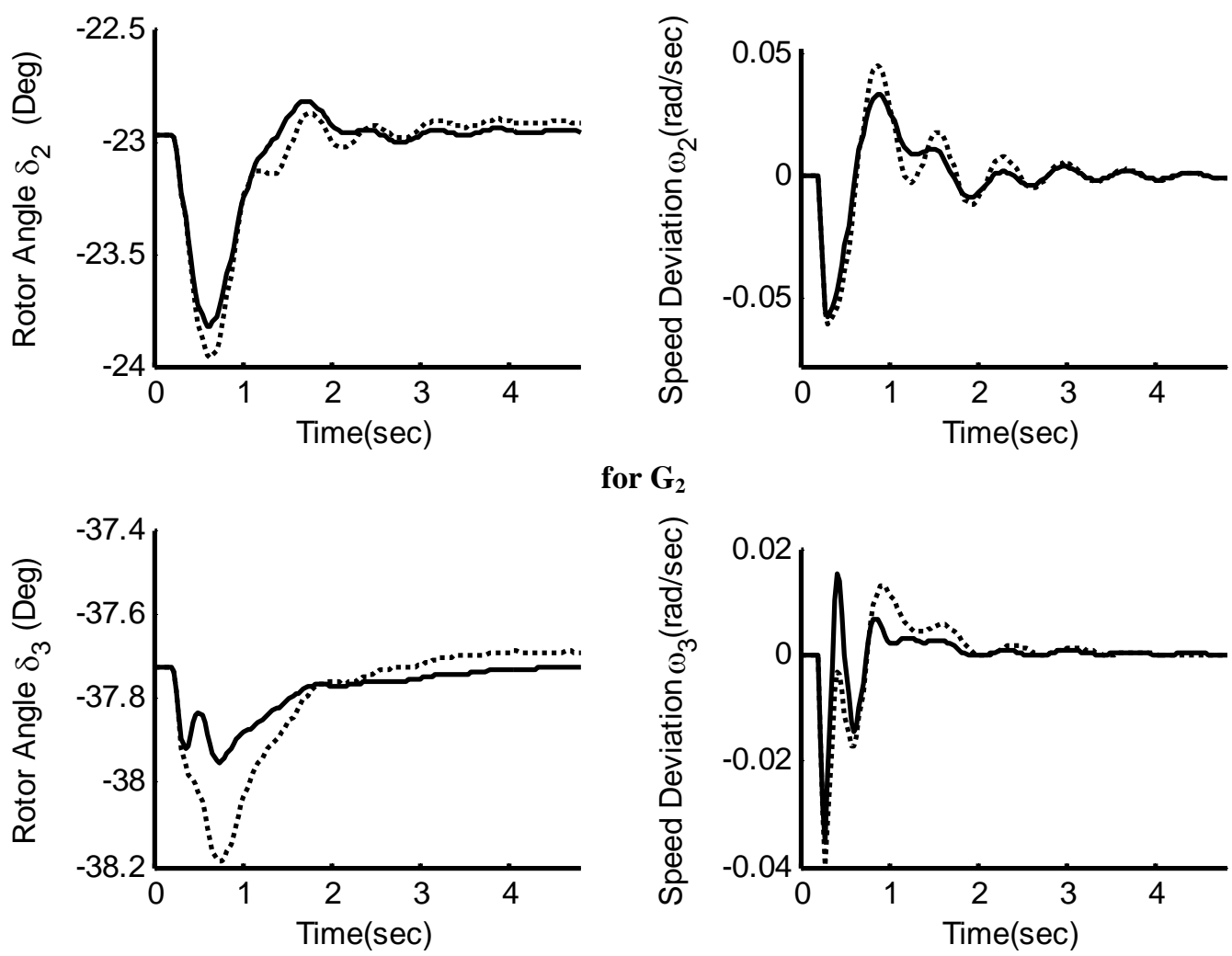

for $G_{2}$
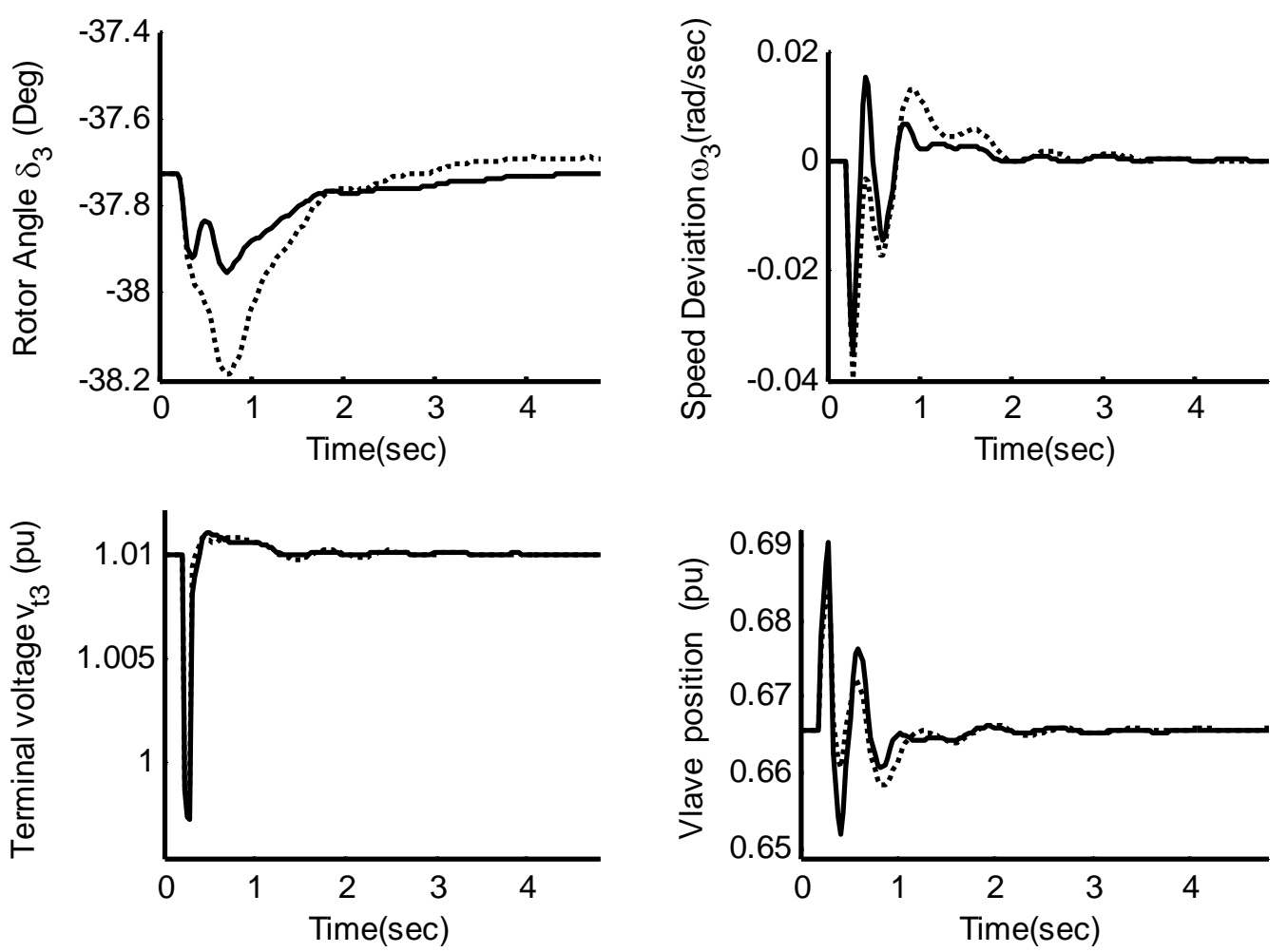

for $G_{3}$
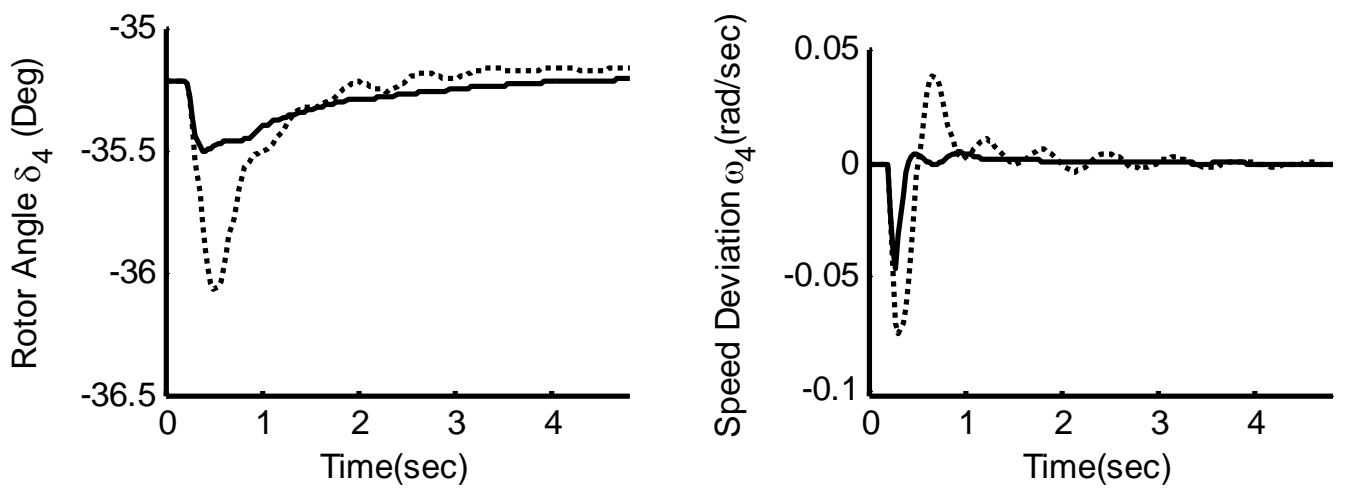

for $\mathbf{G}_{4}$

Fig. 10 Dynamic response to a $10 \%$ load increase at bus 5 for $100 \mathrm{~ms}$ at operating condition 2

- ANN controller on SCG + PSS on conventional units

......... PID controller on SCG + PSS on conventional units 

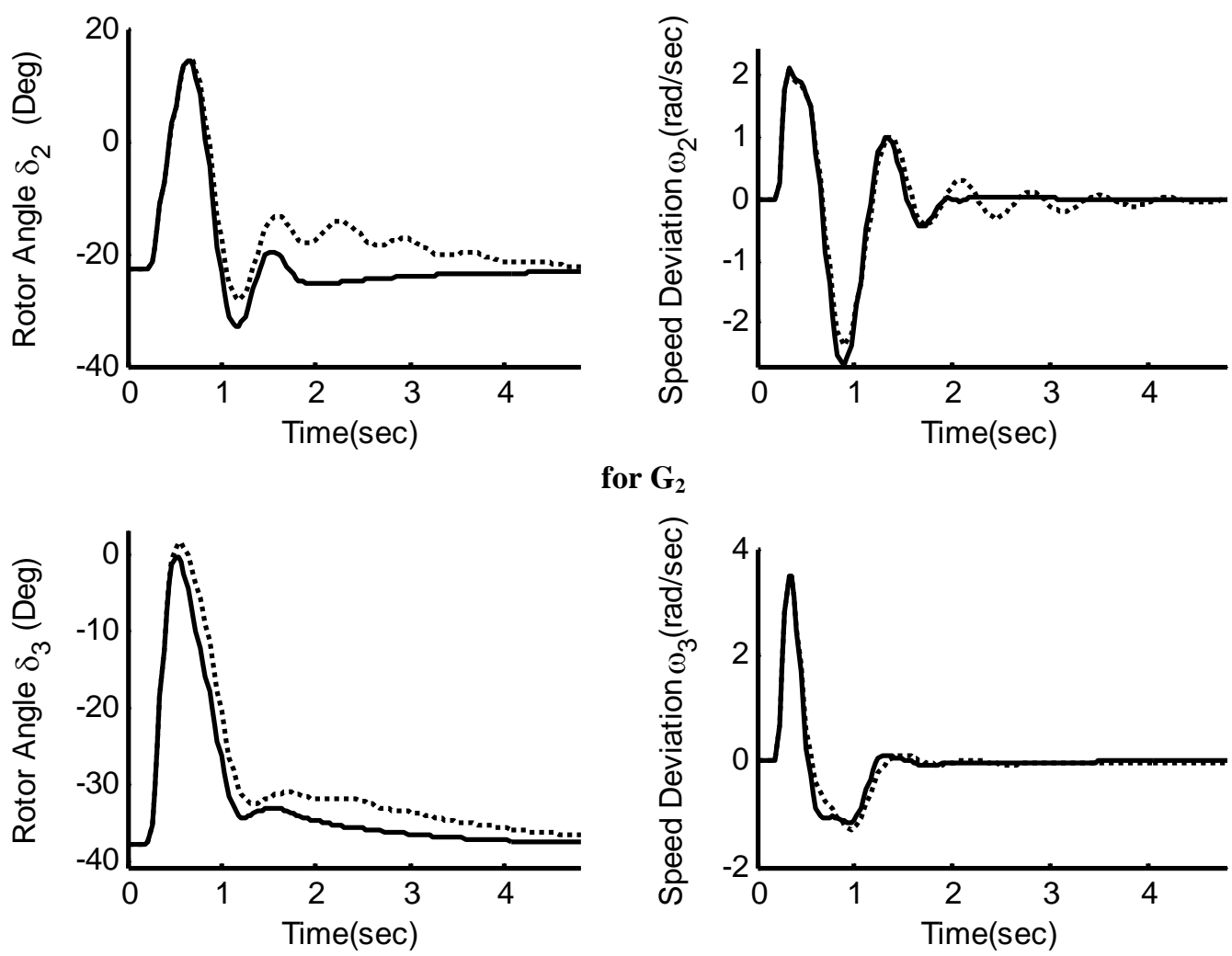

for $G_{2}$
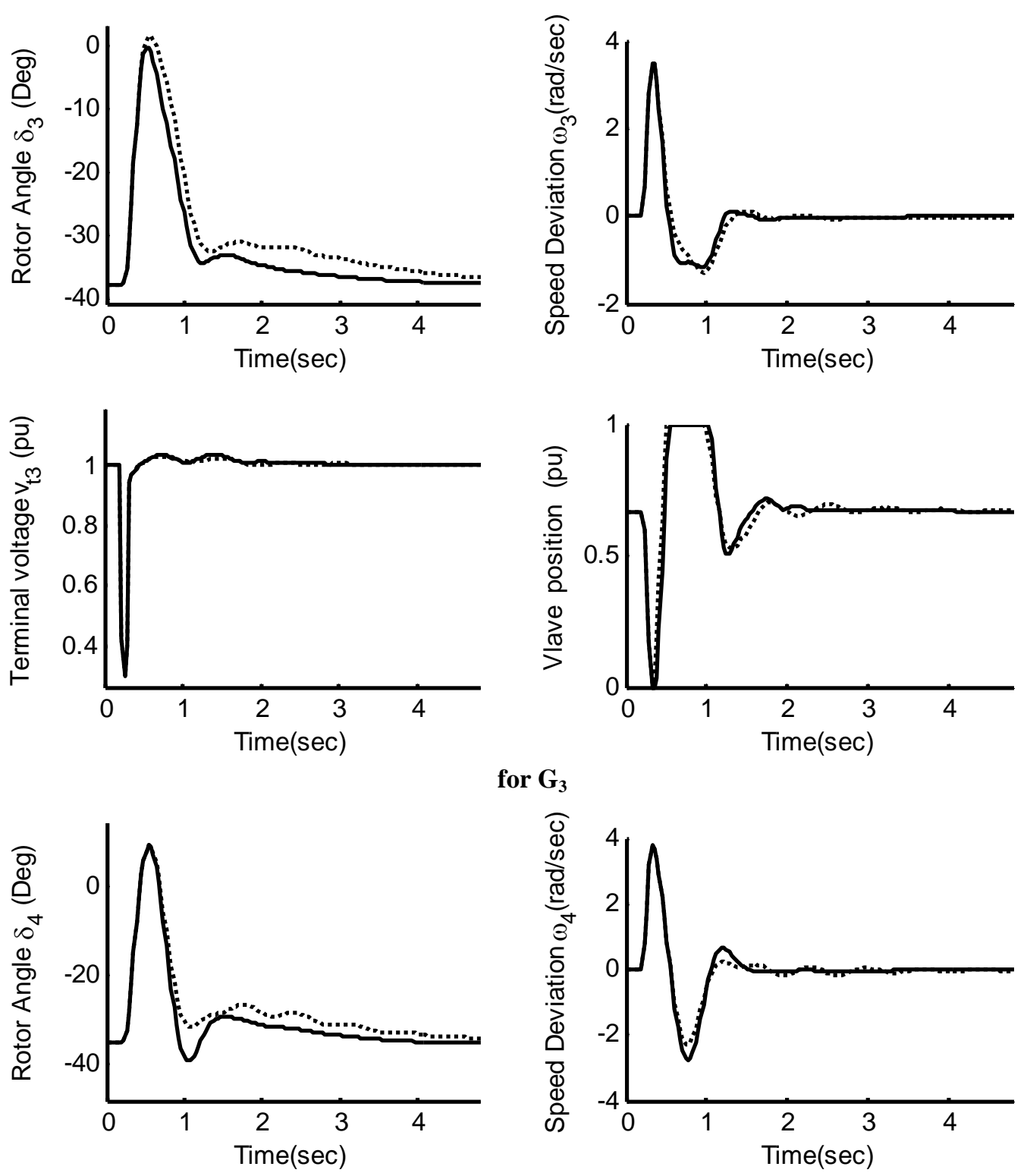

for $\mathbf{G}_{3}$

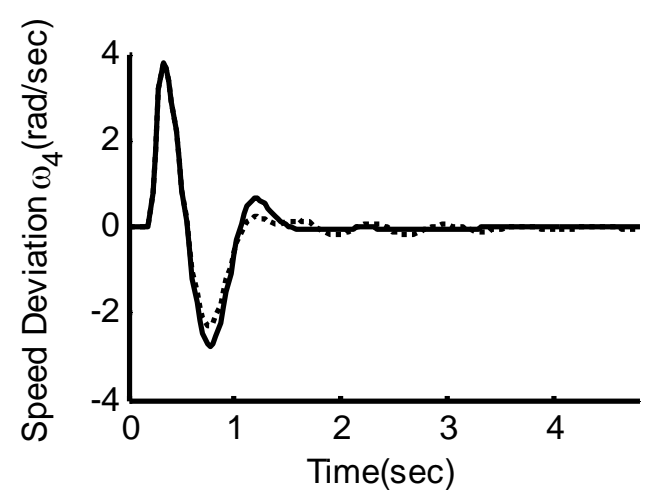

for $\mathbf{G}_{4}$

Fig. 11 Transient response to a 3-phase short circuit for a $100 \mathrm{~ms}$ at $\mathrm{F}_{1}$ at operating condition 2 - ANN controller on SCG + PSS on conventional units .......... PID controller on SCG + PSS on conventional units 